\title{
Experimental Investigation on Drag Effect of Sprinkler Spray to \\ Adjacent Horizontal Natural Smoke Venting
}

\author{
K.Y. Li ${ }^{\text {a }}$, R. Huo ${ }^{\text {b }}$, J. Ji ${ }^{\text {b,** }}$, B.B. Ren ${ }^{\text {b }}$ \\ ${ }^{a}$ Department of Civil and Natural Resource Engineering, \\ University of Canterbury, \\ Christchurch 8140, New Zealand \\ ${ }^{\mathrm{b}}$ State Key Laboratory of Fire Science, \\ University of Science and Technology of China, \\ Hefei 230026, China
}

\begin{abstract}
*Corresponding author: Tel: (86) 551 3607276; Fax: (86) 551 3601669; Email address: jijie232@ustc.edu.cn, steveli@mail.ustc.edu.cn; Postal address: State Key Laboratory of Fire Science, University of Science and Technology of China, Hefei, Anhui, 230026, China
\end{abstract}

\begin{abstract}
Discharge rate of a horizontal adjacent smoke vent under sprinkler spray is experimentally investigated. Temperature of smoke layer and velocity of smoke venting were measured, under different sprinkler operating pressures and smoke venting areas. $\mathrm{CO}$ concentration at the smoke vent center and velocity of vent flow with fresh air outside were recorded in tests under different smoke venting conditions. Experimental results have shown that efficiency of smoke venting is controlled by a combination of smoke buoyancy and drag force of sprinkler spray. Only when buoyancy is greater than drag force the smoke could be extracted by venting. Velocity of smoke venting has shown to decrease as the operating pressure increases. Smoke venting logging, which represents the failure of smoke venting, was experimentally found from certain operating pressure called initial logging pressure. The CO concentration was found to increase after sprinkler was operated as the smoke is constrained in the spray region with horizontal momentum decreased. Negative pressure difference is caused at the vent when there is smoke venting logging, which might practically bring the exterior fresh air into the fire building. Additionally, experiments results have shown that the venting area has little influence on smoke flow under smoke venting logging.
\end{abstract}




\begin{abstract}
Discharge rate of a horizontal adjacent smoke vent under sprinkler spray is experimentally investigated. Temperature of smoke layer and velocity of smoke venting were measured, under different sprinkler operating pressures and smoke venting areas. $\mathrm{CO}$ concentration at the smoke vent center and velocity of vent flow with fresh air outside were recorded in tests under different smoke venting conditions. Experimental results have shown that efficiency of smoke venting is controlled by a combination of smoke buoyancy and drag force of sprinkler spray. Only when buoyancy is greater than drag force the smoke could be extracted by venting. Velocity of smoke venting has shown to decrease as the operating pressure increases. Smoke venting logging, which represents the failure of smoke venting, was experimentally found from certain operating pressure called initial logging pressure. The CO concentration was found to increase after sprinkler was operated as the smoke is constrained in the spray region with horizontal momentum decreased. Negative pressure difference is caused at the vent when there is smoke venting logging, which might practically bring the exterior fresh air into the fire building. Additionally, experiments results have shown that the venting area has little influence on smoke flow under smoke venting logging.
\end{abstract}

\title{
KEYWORDS
}

Sprinkler spray; smoke venting; drag force; buoyancy; smoke venting logging; fire 


\section{Introduction}

Automatic sprinkler systems are required to be installed in buildings such as hotels, factories and shopping malls under prescriptive regulations around the world. The sprinkler systems, which can directly control or suppress the fire, are very reliable in protecting buildings against fires [1-3]. It is also well recognized that smoke and heat vents can play an important role in the fire safety design of buildings besides sprinklers [4,5]. However the buoyancy of the hot smoke layer, which supports the stratification for horizontal natural smoke venting (simply represented by smoke venting), may decrease due to the cooling effect of the water spray. The drag force produced by the water droplets also pulls the stratified smoke layer downward. Both of these two effects might lead to a decrease in smoke venting efficiency, which is a risk to evacuation and fire fighting [6 8].

So far, design codes for sprinklers and roof vents have remained independent and a broadly accepted equivalent design basis for both sprinklers and vents has not been universally recognized [9 11]. However a long-standing debate has been lasted for decades in the fire protection community about the combined use of smoke and heat vents and sprinklers $[7,8]$. The reports in favor of combined use of the two systems usually claim that smoke vents can exhaust the combustion product, decrease the number of operating sprinkler, help the fire service identify the fire location and reduce the building temperature while the sprinkler are inoperative. However, others have claimed that smoke vents will enhance burning rate and delay the activated time of the sprinkler; the combined use is cost ineffective as smoke vents may lose its benefits with sprinkler operation.

Even though numerous studies have been conducted over the past few decades, many questions about the interaction of these devices have yet to be resolved. A full 
scale experimental study was conducted by FMRC in 1956 to investigate the interaction of sprinklers, vents and draft curtains [12]. The tests were conducted in a $36.6 \mathrm{~m} \times 18.3 \mathrm{~m}$ test building with a curtained area of $212 \mathrm{~m}^{2}$. Sprinklers with $3 \mathrm{~m} \times$ $3 \mathrm{~m}$ spacing were installed. The draft curtains were $1.5 \mathrm{~m}$ deep and the roof vents area were $1.5 \mathrm{~m}^{2}$ or $3.0 \mathrm{~m}^{2}$. The test results showed that draft curtain may reduce the number of operating sprinklers to only those within the curtained space, and smoke vents have little effect on sprinkler operating but they are very important for preventing the smoke flowing out to the adjacent curtained space. In the 1960's, research work by Thomas and Hinkley on performance of roof vents led to a tentative recommendation such that the sprinklers should be operated before vents in order to avoid the delay caused by smoke venting [13]. Since then, many large scale experiments were conducted by Suchomel [14], Waterman [15], Hinkley [16], Sheppard [17] and McGrattan [8] respectively to investigate the interaction between the sprinklers system and the vents system. Numerical studies on interaction of roof vents and sprinklers were also carried out by Heselden [18], Hinkley [19,20], Chow [21], McGrattan [8] and Cooper [22,23]. Most of these studies focused on how roof vents affect the activation time, number and location of operating sprinklers; or how the sprinklers affect the activation time and number of automatic roof vents. Little efforts were put to study the effect of sprinklers on smoke venting. The experimental work done at SP $[24,25]$ studied the effect of a single sprinkler on the temperature and velocity of the hot smoke flowing through a $1 \mathrm{~m}$ by $2 \mathrm{~m}$ center ceiling vent. The tests were carried out in a $7.5 \mathrm{~m}$ by $15 \mathrm{~m}$ by $6 \mathrm{~m}$ high channel test space that was opened on two sides. A single sprinkler with a flow rate of either 80 or $100 \mathrm{~L} / \mathrm{min}$ was installed at various locations of the ceiling. The conclusions drawn were that when the sprinkler was installed upstream of the vent (between the fire and the vent), it had a 
"significant" impact on the discharge rate of the vent and when the sprinkler was installed downstream of the vent its influence on vent discharge was regarded as "negligible". The SP experiment mainly focused on the discharge efficiency of the vent far away from the sprinkler spray which is mainly determined by the thickness and the temperature of the smoke layer beneath the vent rather than the drag force of sprinkler spray. Discharge rate of roof vents adjacent to the sprinkler spray was experimentally studied by McGrattan [8] with a velocity probe positioned at center of the vents in 1998. Unfortunately, the velocity data was deemed to be unreliable in terms of the statements by McGrattan [8] and there was no means to directly measure the discharge rate of smoke venting in those tests. It should also be noted that before the mathematical model for sprinkler spray was built by Sheppard in 2002, drag force of droplets was hard to be calculated that the interaction of sprinkler spray and smoke layer was absolutely unknown [26,27]. Therefore, effect of sprinkler spray on the behavior of smoke flow could not be analyzed mathematically.

Full scale experiments were conducted in this study to investigate the drag effect of sprinkler spray on the efficiency of adjacent smoke venting, where 'adjacent' means that the distance between the smoke vent and the sprinkler does not exceed the radius of sprinkler spray coverage area. The velocity of smoke flow through the roof vent, the smoke layer thickness and the temperature, were experimentally measured with various sprinkler operating pressures. The resistant effect of drag force was then analyzed using the experimental results. Additionally, $\mathrm{CO}$ concentrations at the vent center were measured in the experiments to analyze the smoke flow states.

\section{Measurement of smoke venting velocity}

\subsection{Velocity of smoke venting without sprinkler spray}


Fire room with a roof vent and a make-up air intake nearby the floor is shown in Figure 1. The pressure difference at the location of roof vent and make-up air intake are expressed respectively as [28,29]

$$
\begin{gathered}
\Delta P_{I N-\text { OUT }}=\left(H-H_{N}\right)\left(\rho_{a}-\rho_{g}\right) g \\
\Delta P_{\text {OUT-IN }}=\left(H_{N}-H_{L}\right)\left(\rho_{a}-\rho_{g}\right) g
\end{gathered}
$$

Velocities of smoke venting and make-up air are consequently deduced to be

$$
\begin{aligned}
& V_{V}=\sqrt{\frac{2 \Delta P_{I N-O U T}}{\rho_{g}}}=\sqrt{\frac{2\left(H-H_{N}\right)\left(\rho_{a}-\rho_{g}\right) g}{\rho_{g}}} \\
& V_{a}=\sqrt{\frac{2 \Delta P_{\text {OUT-IN }}}{\rho_{a}}}=\sqrt{\frac{2\left(H_{N}-H_{L}\right)\left(\rho_{a}-\rho_{g}\right) g}{\rho_{a}}}
\end{aligned}
$$

Thus the mass flow rates are

$$
\begin{gathered}
\dot{m_{V}}=C_{d} A_{V} \rho_{g} V_{V}=C_{d} A_{V} \rho_{g} \sqrt{\frac{2\left(H-H_{N}\right)\left(\rho_{a}-\rho_{g}\right) g}{\rho_{g}}} \\
\dot{m}_{a}=C_{d} A_{f} \rho_{a} V_{a}=C_{d} A_{f} \rho_{a} \sqrt{\frac{2\left(H_{N}-H_{L}\right)\left(\rho_{a}-\rho_{g}\right) g}{\rho_{a}}}
\end{gathered}
$$

where $C_{d}$ is taken to be 0.61 as recommended by SFPE [5]. Conservation of mass leads to

$$
\dot{m}_{V}=\dot{m}_{a}
$$

Substituting Equation (7) with Equation (5) and (6) gives

$$
A_{V} \sqrt{\rho_{g}\left(H-H_{N}\right)}=A_{f} \sqrt{\rho_{a}\left(H_{N}-H_{L}\right)}
$$

The height of natural plane is then deduced to be

$$
H_{N}=\frac{A_{V}{ }^{2} \rho_{g} H+A_{f}{ }^{2} \rho_{a} H_{L}}{A_{V}{ }^{2} \rho_{g}+A_{f}{ }^{2} \rho_{a}}
$$

From this equation, $H_{N}$ equals approximately to $H_{L}$ when $A_{V} \ll A_{f}$, which is 
referred to as the condition where the make-up area is much larger than the venting area. As a result, the velocity of smoke venting is expressed as

$$
V_{V}=\sqrt{\frac{2 h\left(\rho_{a}-\rho_{g}\right) g}{\rho_{g}}}
$$

Since the smoke could be assumed to be ideal gas, Equation (10) is converted to

$$
V_{V}=\sqrt{\frac{2 h\left(T_{g}-T_{a}\right) g}{T_{a}}}=\sqrt{\frac{2 h \overline{\Delta T} g}{T_{a}}}
$$

\subsection{Measurement of smoke venting velocity with target flowmeter}

Right side of Equation (10) represents the effect of layer buoyancy on smoke venting when the make-up area is much greater than the venting area on the roof. However drag and cooling effect might mainly reduce the buoyancy rather than changing the product concentrations while the water droplets did not act on combustion $[24,25]$. Thus the flow velocity which represents the efficiency of smoke venting might change as drag and cooling effect were brought by sprinkler spray into the smoke layer. There are different sorts of instruments such as Pitot, Bidirectional micro-pressure probe and Hot-wire anemometer available for recording the velocity of smoke venting. Unfortunately, high humidity of the smoke would produce condensed water when the smoke flow was cooled by the instrument. The condensed water will block the measuring tube (Pitot, Bidirectional micro-pressure probe) or cover mesh (Hot-wire anemometer) and therefore leads to false results. In order to resolve this problem, new measuring device must be incorporated in the experiment. In this experiment, a target flowmeter, which has been wildly used to measure velocity or volumetric flow rate of dirty liquid or gas (wet smoke is regarded as dirty gas) [30,31], was used.

The target flowmeter determine the smoke velocity by measuring the amount of 
force exerted by the fluid on a target suspended in the flow stream. As shown in Figure 2(a), for smoke flow with velocity, $V_{V}$, the force, $F_{d}$, is given by force equation of incompressible flow [31]

$$
F_{d}=C_{T} A_{T} \frac{\rho_{g} V_{V}^{2}}{2}
$$

where $C_{T}$ is the resistant coefficient to be determined experimentally based on the flow conditions and the geometry of the target element. For flat plate, $C_{T}$ is typically 1.28 [31]. For a given design, $A$ and $C_{T}$ are constant. If the fluid density, $\rho_{g}$, is also constant, the velocity $V_{V}$ is solely a function of $F_{d}$ to the power of 0.5 , which is expressed as

$$
V_{V}=\sqrt{\frac{2 F_{d}}{C_{T} A_{T} \rho_{g}}}
$$

However the density of smoke flow may not be constant as the smoke temperature varies in different tests. On the other hand, density of smoke is not uniform in the depth direction of smoke layer. Therefore, the measured velocity should be revised to comply with the density of smoke flowing out whose temperature is measured with thermocouple at the vent plane. As the standard working temperature of the target flowmeter is $298 \mathrm{~K}$, the density of smoke is deduced with the assumption of incompatible ideal gas

$$
\rho_{g M}=\frac{T_{0}}{T_{g M}} \rho_{0}
$$

As a result, the revised (or actual) velocity can be calculated with the measured velocity using Equation (15) by combining in terms of Equation (13) and (14)

$$
V_{R V}=\sqrt{\frac{2 T_{g M} F_{d}}{C_{T} A_{T} T_{0} \rho_{0}}}=\sqrt{\frac{T_{g M}}{T_{0}}} V_{V M}
$$


As shown in Figure 2(a), the electronic transmitter converts the force to the velocity of fluid flow [30,31]. The target flowmeter was installed on the roof with the target located at the center of the smoke vent as shown in Figure 2(b). To avoid the impact of upward moving droplets, the target was elevated $10 \mathrm{~cm}$ vertically from the vent plane.

\section{Experimental}

The experimental set up is shown in Figure 3. It consists of two parts, the burning cabin and the sprinkler cabin. As shown in Figure 3, pool fires are burned in the burning cabin to generate an initial stable smoke layer in the upper part of the sprinkler cabin. The burning cabin is $4 \mathrm{~m}$ long, $2 \mathrm{~m}$ wide and $2.5 \mathrm{~m}$ high. Six air supplying intakes with $0.8 \mathrm{~m} \times 0.4 \mathrm{~m}$ opening are located on both sides of the cabin.

The sprinkler cabin is a cube with identical length, width and height of $4.2 \mathrm{~m}$. Smoke curtains with height of $2.0 \mathrm{~m}$ are installed below the top of the cabin to maintain an initial stable smoke layer. A gauge with height of $4.2 \mathrm{~m}$ is inserted in front of the cabin to measure the length of the downward smoke plume as shown in Figure 3(b).

As shown in Figure 3(c), ZSTP-15 Sprinkler with nozzle diameter of $12.7 \mathrm{~mm}$ is used for the tests. The sprinkler with the flow rate coefficient of 80 is made by copper alloys. The sprinkler is installed in the central of the sprinkler cabin roof with installation type of standard pendant. Pressure reducing valve and pressure transmitter are installed on the pipeline to control the sprinkler operating pressure with an accuracy of $0.002 \mathrm{MPa}$. A digital video camera is used to record the tests.

As shown in Figure 4, two different adjacent roof vent configurations are used in tests. Tests with one roof vent are conducted to investigate the impact of sprinkler spray on smoke venting. Tests with three adjacent roof vents are conducted to 
investigate the effect of smoke venting area. Temperature of smoke is measured by the thermocouples trees installed under the center of each vent. The vertical interval of the thermocouples is $0.3 \mathrm{~m}$. The thermocouples are covered by saddle steel waterproofing caps which are used to prevent the water droplets from hitting the thermocouples directly, as shown in Figure 3(d). Experiments with and without these caps have been conducted to investigate the influence of the caps under the absence of sprinkler spray. The result shows there is no impact on the measured temperature since the caps are very small. A flat target element with length of $10 \mathrm{~cm}$, width of 10 $\mathrm{cm}$ and thickness of $0.3 \mathrm{~mm}$ is installed on the target flowmeter to measure the velocity of smoke venting. The experimental results must be revised manually by using Equation (15) as there is not temperature sensor in the target flowmeter for selfcalibration. In this paper a Testo350XL gas concentration analyser as well as a KANOMAX hot-wire anemometer are applied in the test with different smoke venting conditions in addition to the target flowmeter to investigate the variation of $\mathrm{CO}$ concentration at the vent center and vent flow velocity. The results are applied to analyze the smoke flow field under different spray conditions. The target flowmeter, the gas analyzer and the anemometer have been installed at the vent on the right of sprinkler, which has been labeled as "Measured vent" as shown in Figure 4.

A total of 36 tests was conducted with two different fire heat release rates. Diesel was used as the burned material of the pool fires. Heat release rate of the pool fires is determined by the mass loss rate measured by an electronic balance and the heat value of the diesel which is taken to be $42000 \mathrm{~kJ} / \mathrm{kg}$. Factor of the burning efficiency is 0.8 in terms of the researches in cabin [32]. As a result, heat release rates used in experiment are calculated to be $248 \mathrm{~kW}$ and $476 \mathrm{~kW}$ for different pool fires. In test, the sprinkler spray is activated when the upper part of the sprinkler cabin is filled with 
a stable smoke layer. The total burning time of each test was about $300 \mathrm{~s}$. Operating pressure of the sprinkler varied from 0.03 to $0.15 \mathrm{MPa}$.

\section{Results and discussion}

\subsection{Velocity of smoke venting under sprinkler spray}

Upper part of the sprinkler cabin was filled with smoke after ignition without sprinkler spray for 50 60 s. After which the smoke started to flow out of the cabin through the bottom edge of the draft curtain. The velocity of smoke venting, which can be calculated by Equation (11) with smoke layer height of $2 \mathrm{~m}$, would reach its peak at this moment (476 kW, whereas the peak time for $248 \mathrm{~kW}$ is around $80 \mathrm{~s})$. The velocity of smoke venting is measured by target flowmeter, which are plotted in Figure 5. As shown in Figure 5, the measured peak velocity is $1.36 \mathrm{~m} / \mathrm{s}$ and $1.52 \mathrm{~m} / \mathrm{s}$ for heat release rate of $248 \mathrm{~kW}$ and $476 \mathrm{~kW}$ respectively. If there was no sprinkler spray, velocity would not change significantly in the test.

Droplets of sprinkler spray might cool the smoke layer and decrease its buoyancy by drag force. Consequently, sprinkler operating would lead to a decrease of smoke venting velocity. As shown in Figure 5, velocity reached around $1.15 \mathrm{~m} / \mathrm{s}$ and 1.50 $\mathrm{m} / \mathrm{s}$ before sprinkler was operated when heat release rate was $248 \mathrm{~kW}$ and $476 \mathrm{~kW}$ respectively. The velocity decreased sharply within half a minute after sprinkler was being operated. After this period, the velocity remained relatively stable. This period could be regarded as the steady state of smoke venting under sprinkler spray. When the fuel was running out, smoke venting velocity began to decrease till zero velocity; the start of running out was about $250 \mathrm{~s}$ in $248 \mathrm{~kW}$ tests and $200 \mathrm{~s}$ in $476 \mathrm{~kW}$ tests. The velocity of steady state was found to decrease as the sprinkler operating pressure increases. For $248 \mathrm{~kW}$ tests, the steady state velocity was about $0.8 \mathrm{~m} / \mathrm{s}$ when the 
operating pressure was $0.03 \mathrm{MPa}$. The velocity decreased to around $0 \mathrm{~m} / \mathrm{s}$ as operating pressure increased to $0.09 \mathrm{MPa}$. As shown in Figure 5(a), when the operating pressure is higher than $0.09 \mathrm{MPa}$, the velocity of smoke venting remains 0 $\mathrm{m} / \mathrm{s}$ and no smoke was going to be vent extracted at steady state. This is named as "smoke venting logging". The smoke couldn't flow out of the building through vents under "smoke venting logging", which is practically dangerous to the evacuating people in fire. The operating pressure at which smoke venting logging started was named as "initial logging pressure". Therefore, the initial logging pressures in $248 \mathrm{~kW}$ and $476 \mathrm{~kW}$ tests are $0.09 \mathrm{MPa}$ and $0.13 \mathrm{MPa}$ respectively as seen in Figure 5.

Experimentally measured data are summarized in Table 1. Time average was made for steady state velocity and is labeled as $V_{V M}$ in Table 1 so that the revised velocity, $V_{V R}$, can be calculated by Equation (15). Temperature measured by the top thermocouple shown in Figure 3(a) is applied to be $T_{g M}$. It can be seen that as the operating pressure increases, cooling and drag effect of the sprinkler spray increase. As a result, the pressure difference decreases at the vent plane and therefore the smoke venting velocity decreases. This trend can be observed in Figure 6. As shown in the figure, the revised velocity decreases as the operating pressure increases. As the heat release rate is higher, the velocity in Tests $\mathrm{PH}$ is greater than that in Tests PF. As shown in Table 1, temperature rise of smoke layer below the vent does not equal to 0 $\mathrm{K}$ under initial logging pressure or even higher ones. For example in Test PF7, PH6, and $\mathrm{PH} 7$, the temperature rise is $6.0 \mathrm{~K}, 9.9 \mathrm{~K}$, and $10.3 \mathrm{~K}$ respectively. This implies that buoyancy of smoke layer can occur while smoke venting logging in these tests. Therefore, it can be concluded that drag force may play an important role in adjacent smoke venting logging besides cooling effect. As the operating pressure increases to the initial logging pressure, drag effect exceeds the buoyancy, which leads to smoke 
venting logging. As seen in the experiment PF10 which had been shown with smoke venting logging, smoke venting without sprinkler spray causes a plume above the vent such that the target flowmeter could not be visual under this condition as shown in Figure 7(a). After sprinkler was operated and smoke venting logging occurred, the target and the extension rod could be seen very clearly, as shown in Figure 7(b).

In theory, the pressure difference at the roof vent, which is caused by the buoyancy smoke layer, may push the smoke to flow upward and eventually lead to smoke venting. However the spray drag force will pull the smoke down and reduce the buoyant effect of the smoke layer. Therefore the pressure difference drops down whenever the sprinkler is operated to a certain smoke layer. On the other hand, the spray drag force is determined by both of the velocity and the quantity of the droplets which increase as the operating pressure increases. So, as to a certain smoke layer, the pressure difference at the vent decreases while the operating pressure increases. Consequently, as the operating pressure keeps increasing, the drag force is eventually greater than the buoyancy, which leads the smoke to flow downward rather than venting. A similar result that the mass flow rate decreased under sprinkler spray was found by McGrattan [8] from his simulations. Therefore the experimental result seems to be reasonable. Compared to previous research, this study increases the operating pressure up to a higher value causing smoke venting logging, which haven't been investigated before.

\subsection{CO concentration in typical experiments}

The carbon monoxide concentrations at the center of the Measured vent in Test PF0, PF5, and PF10, which represent the states of "no sprinkler spray", "no smoke venting logging under sprinkler spray" and "smoke venting logging" respectively, were measured by the gas analyzer. The data were recorded in Figure 8 as well as in 
Table 1. It is interesting to note that the $\mathrm{CO}$ concentration of smoke increased after sprinkler is operated. As shown in Figure 8, the measured $\mathrm{CO}$ concentration of the smoke venting flow is approximately 28 PPM for Test PF0. The value drops sharply after sprinkler is operated during Test PF5 then suddenly increased to a higher value of 46 PPM which is about 1.5 times of Test PF0. The water spray, which has prevented the smoke from flowing out of the sprinkler cabin through the bottom edge of smoke curtain by decreasing its horizontal velocity, is analytically attributed to be the main reason of the $\mathrm{CO}$ increase. Actually when smoke is downward dragged by the water spray with vertical momentum decrease, its horizontal momentum might be reduced as well with "smoke logging" in the spray region [22,27]. At this moment the lower part of sprinkler cabin is filled with smoke under sprinkler spray, which might weaken the entrainment of fresh air outside and thus lead to an increase of carbon monoxide. CO concentration in Test PF10 drops to 5 PPM after sprinkler operation. The smoke venting logging in this test prevented smoke from flowing out through roof vent, which caused a major decrease of $\mathrm{CO}$ concentration in gas analyzer as no smoke flowed through the measuring probe. Time average is made between $100 \mathrm{~s}$ to $200 \mathrm{~s}$ which is considered as the steady state as shown in Figure 8. The results are recorded in Table 1.

\subsection{Character of venting flow under smoke venting logging}

Above statements presents that when wet smoke flowed through the hot-wire anemometer, the condensed water would block the cover mesh of its probe, which then causes a decrease of measured velocity since the smoke flowing through the probe is reduced. However the hot-wire anemometer could still be used to measure the flow velocity if the flowing gas was clean air rather than smoke. So the KANOMAX hot-wire anemometer is applied in typical experiments to study the 
character of venting flow under smoke venting logging. As shown in Figure 9, for Test PH1 with operating pressure of $0.03 \mathrm{MPa}$, the measured velocity decreases after sprinkler being operated and no steady state is found in the experiment. However this was not observed in Figure 5. In Test PH6 and PH7, since there is smoke venting logging and no smoke flows through the probe, the measured velocities in Figure 5 should drop to zero. However the measured velocity doesn't drop to zero in these two experiments as seen in Figure 9. This is because the hot-wire anemometer can measured bi-directional flow velocity. So the anemometer can measure the velocity if the venting flow is formed by the fresh air outside. Consequently, it is deduced that the vent flow under smoke venting logging is caused by the fresh air outside of the sprinkler cabin being sucked into the vent due to the negative pressure difference which is resulted from the drag force being greater than the buoyancy. This negative air flow is a concern in actual fire as it might benefit the combustion and the smoke spread. Theoretically, as the smoke moves downwardly under smoke venting logging condition, the outside air also flows downwardly due to the continuity. As the operating pressure increases, the effect of downward movement increases. Therefore more fresh air is sucked into the sprinkler cabin. As shown in Figure 9, velocity of Test PF7 is greater than that in Test PF6 due to the higher operating pressure which enhances the downward trend of the smoke flow. Thus, it can be concluded that the flow rate of sucked air increases if the operating pressure increases under smoke venting logging, which is likely to increase the risk of fire.

\subsection{Comparison of different smoke venting conditions}

The number of adjacent roof vents at the same distance from sprinkler is increased to 3 in Tests PG and PI as shown in Figure 4(b). Velocity of smoke venting is recorded at the Measured vent. The velocity was compared in Figure 10. It was 
found that the velocity with three vents is relatively lower than the velocity with a single vent before smoke venting logging initiate. While the operating pressure increases, difference between the two velocities decreases. It was also found that the velocity decreases as the operating pressure increases under both smoke venting conditions. Smoke venting logging occurs under the same operating pressure which is determined by the heat release rate. Initial logging pressure are highlighted by the circles in Figure 10, which is $0.09 \mathrm{MPa}$ for tests with heat release rate of $248 \mathrm{~kW}$ and $0.13 \mathrm{MPa}$ for tests with heat release rate of $476 \mathrm{~kW}$. Figure 11 presents the average temperature rise of the smoke layer beneath the Measured vent. It can be seen that the average temperature rise beneath the vent is different when smoke venting is not logging. This is because that before smoke venting logging occurs, as the smoke venting area increases, total volumetric flow rate of smoke venting increases. As shown in Figure 12, single vent, under which total volumetric flow is less because of less smoke venting area, would lead to less heat loss from the sprinkler cabin and thus higher temperature rise of smoke layer. The temperature rise difference decreases while the operating pressure increases and becomes almost zero when smoke venting logging initiates. Intuitively, it is expected that the smoke venting area can affect the efficiency when there is no logging, which would lead to different velocity and temperature rises. When smoke venting is logged, the roof vents would not affect the smoke flow dragged down by the sprinkler spray, which leads to the same initial logging pressure and temperature rise. So, it can be concluded that smoke venting condition would have insignificant impact on the smoke flow field under smoke venting logging condition as the vents have lose its venting function already. No matter how large the smoke venting area is, the flow fields of smoke would be very similar under smoke venting logging condition. Figure 13 shows the smoke flow field 
in Test PH7 and PI7 which were under smoke venting logging. It can be seen from Figure 13 that the smoke is pulled down and flows out from the lower part of sprinkler cabin. No smoke has flowed out through the roof vents in these two tests. Therefore, smoke venting area has no significant effect on the smoke flow.

\section{Conclusions}

Effect of adjacent smoke venting under sprinkler spray was experimentally studied in this paper. Full scale experiments were carried out to investigate the variation of smoke venting velocity under different operating pressures of a sprinkler. With the increase of the sprinkler operating pressure, the velocity of smoke venting decreases. Smoke venting function of the roof vent is going to be lost from certain operating pressure called "initial logging pressure", which might cause "smoke venting logging". The smoke venting logging would lead to measured velocity by target flowmeter of $0 \mathrm{~m} / \mathrm{s}$; then no smoke flowed out through the roof vents. Drag effect of the sprinkler spray was found to have a significant impact on discharge rate of smoke venting since the temperature rise of the smoke layer beneath the roof vent was not zero under smoke venting logging. Drag force pulls the smoke down while buoyancy pushes it up; and smoke venting logging might happen when the drag force was greater than the buoyancy. The sprinkler spray decreases the horizontal momentum of the smoke flow therefore prevent it from flowing out of the spray region, which leads to an increase of $\mathrm{CO}$ concentration. When there is no smoke venting logging, the increase could be recorded by measuring the smoke at the roof vent. Actually, the vent flow velocity is not zero under smoke venting logging condition. Fresh air outside will be sucked into the vent whenever there is negative pressure difference caused by smoke venting logging. Different smoke venting areas 
are also considered in the experiment. Results show that the smoke venting areas would lead to difference of velocities and smoke layer temperature rises when smoke venting is not logged and would have no significant effect on the smoke flow state under smoke venting logging.

Current research reveals the mechanism of adjacent smoke venting under sprinkler spray. Practically combination of sprinkler and smoke venting systems in building should be aware with the smoke venting logging problem which might happen in actual fires. Further works, which focus on the regulation of $\mathrm{CO}$ concentration variation, the cooling effect and predicting the temperature distribution of smoke layer in spray region, are ongoing and will be reported later.

\section{Acknowledgements}

This work was supported by the Young Teachers Program of Southwest Jiaotong University under Grant No. 2008Q041 and the Natural Science Foundation of China (NSFC) under Grant No. 50904055. 


\section{Nomenclature}

$A_{f}$ make-up air intake area $\left(\mathrm{m}^{2}\right)$

$A_{T}$ target area $\left(\mathrm{m}^{2}\right)$

$A_{V}$ roof vent area $\left(\mathrm{m}^{2}\right)$

$C_{d}$ flow coefficient

$C_{T}$ resistant coefficient of target

$F_{d}$ force on the target element $(\mathrm{N})$

$g$ acceleration due to gravity $\left(\mathrm{ms}^{-2}\right)$

$h$ initial thickness of the smoke layer (m)

$H$ height of the room (m)

$H_{L}$ height of the smoke layer interface (m)

$H_{N}$ height of the natural plane respectively (m)

$\dot{m}_{a}$ mass flow rate of make-up air $\left(\mathrm{kgs}^{-1}\right)$

$\dot{m}_{V}$ mass flow rate of smoke venting $\left(\mathrm{kgs}^{-1}\right)$

$\Delta P_{I N-O U T}$ pressure difference at the vent $(\mathrm{Pa})$

$\Delta P_{\text {OUT-IN }}$ pressure difference at the make-up air intake $(\mathrm{Pa})$

$\overline{\Delta T}$ average temperature rise of the smoke layer $(\mathrm{K})$

$T_{0}$ standard working temperature of target flowmeter (K)

$T_{a} \quad$ ambient temperature (K)

$T_{g} \quad$ average smoke layer temperature (K)

$T_{g M}$ measured temperature at the vent (K)

$V_{a}$ velocity of supply air $\left(\mathrm{ms}^{-1}\right)$

$V_{V}$ velocity of smoke venting in zone model $\left(\mathrm{ms}^{-1}\right)$ 


$$
\begin{aligned}
& V_{V R} \text { actual velocity of smoke venting }\left(\mathrm{ms}^{-1}\right) \\
& V_{V M} \text { measured velocity of smoke venting }\left(\mathrm{ms}^{-1}\right)
\end{aligned}
$$

\section{Greek symbols}

$\rho_{0}$ standard working density of target flowmeter $\left(\mathrm{kgm}^{-3}\right)$

$\rho_{a}$ air density at ambient temperature $\left(\mathrm{kgm}^{-3}\right)$

$\rho_{g}$ density of the smoke $\left(\mathrm{kgm}^{-3}\right)$

$\rho_{g M}$ density of the smoke at the vent $\left(\mathrm{kgm}^{-3}\right)$ 


\section{References}

[1] K.C. Chung, H.S. Tung, A Simple Model for Smoke Filling Time Calculation with Sprinkler Effects, J. Fire Sci. 23(2005) 279-301.

[2] D.T. Butry. Economic Performance of Residential Fire Sprinkler System, Fire Technol. 45 (2009) 117-143.

[3] W.K. Chow, B. Yao. Numerical Modeling for Interaction of a Water Spray with Smoke Layer. Numer. Heat Tr. 39(2001) 267-283.

[4] J.H. Klote, J.A. Milke, Principle of Smoke Management, American Society of Heating, Refrigerating and Air-Conditioning Engineers, Atlanta, GA, 2002..

[5] SFPE Handbook of Fire Protection Engineering, third ed., Boston, MA, USA Society of Fire Protection Engineers and National Fire Protection Association, 2002.

[6] A.J.M. Heselden, The Interaction of Sprinkler and Roof Venting in Industrial Buildings the Current Knowledge, Building Research Establishment, Borehamwood, UK, 1984.

[7] C.L. Beyler, L.Y. Cooper, Interaction of Sprinkler with Smoke and Heat Vents, Fire Technol., 37 (2001) 9-35.

[8] K.B. McGrattan, A. Hamins, D. Stroup, Sprinkler, Smoke \& Heat Vent, Draft Curtain Interaction -- Large Scale Experiments and Model Development, Gaithersburg National Institute of Standards and Technology, 1998.

[9] NFPA13, Standard for the Installation of Sprinkler System, 2002 ed., USA National Fire Protection Association, 2002.

[10] NFPA231C, Standard for Rack Storage of Materials, 2002 ed., USA National Fire Protection Association, 2002.

[11] NFPA204M, Guide for Smoke and Heat Venting. 2002 ed., USA National Fire Protection Association, 2002.

[12] Factory Mutual Engineering Corporation, Heat Vents and Fire Curtains, Effect in Operation of Sprinklers and Visibility, Factory Mutual Research Corporation, Norwood MA, 1956.

[13] P.H. Thomas, P.L. Hinkley, Design of Roof-venting Systems for Single-story Buildings, Technical Paper No. 10, Building Research Establishment (BRE), Fire Research Station (FRS), Borehamwood, England, 1964. 
[14] M.R. Suchomel, A Preliminary Study of Factors Influencing the Use of Vents with OrdinaryDegree Sprinklers, Technical report, Underwriters' Laboratories for the National Board of Fire Underwriters, File NC449, Assignment 63K4340, July 1964.

[15] T.E. Waterman, C.E. Foxx, K.R. Mniszewski, and D.L. Eacret, Fire Venting of Sprinklered Buildings. Technical Report IITRI Project J08385, IIT Research Institute, 10 West 35th Street, Chicago, Illinois 60616, July 1982. Prepared for the Fire Venting Research Committee.

[16] P.L. Hinkley, G.O. Hansell, N.R. Marshall, and Harrison R, Sprinklers and Vents InteractionExperiments at Ghent. Fire Surveyor, (1992) 18-23.

[17] D.T. Sheppard, D.R. Steppan, Sprinkler, Heat \& Smoke Vent, Draft Curtain Project- Phase 1 Scoping Tests, Technical report, Underwriters Laboratories, Inc., Northbrook, Illinois, May 1997.

[18] A.J.M. Heselden, Taking a New Look at Combining Sprinklers Systems with Venting. Fire, October (1985) 42-43.

[19] P.L. Hinkley, The Effect of Vents on the Open of the First Sprinklers, Fire Saf. J., 11(1986) $211-225$.

[20] P.L. Hinkley, The Effect of Smoke Venting on the Operation of Sprinklers Subsequent to the First, Fire Saf. J., 14(1989) 221-240.

[21] W.K. Chow, Y.L. Cheung, Simulation of Sprinkler-hot Layer Interaction Using a Field Model, Fire Mater., 18(1994) 359-379.

[22] L.Y. Cooper, The Interaction of an Isolated Sprinkler Spray and a Two-Layer Compartment Fire Environment. Phenomena and Model Simulations, Fire Saf. J., 25(1995) 89-107.

[23] L.Y. Cooper, The Interaction of an Isolated Sprinkler Spray and a Two-Layer Compartment Fire Environment. Int. J. Heat Mass Tran., 38(1995) 679-690.

[24] H. Ingason, S. Olsson, Interaction between Sprinklers and Fire Vents, Technical report, Sweden Swedish National Testing and Research Institute (SP), 1992.

[25] B. Persson, H. Ingason, Modeling of Interaction between Sprinklers and Fire Vents-Present knowledge, Technical report, Sweden Swedish National Testing and Research Institute (SP), 1996.

[26] D.T. Sheppard, Spray Characteristics of Fire Sprinklers. PhD dissertation, Northwestern 
University, Evanston, 2002.

[27] K.Y. Li, L.H. Hu, R. Huo, Y.Z. Li, Z.B. Chen, X.Q. Sun, S.C. Li, A Mathematical Model on Interaction of Smoke Layer with Sprinkler Spray, Fire Saf. J., 44(2009) 96-105.

[28] D. Drysdale, An introduction to fire dynamics, second ed., USA, New York Wiley, 1999.

[29] B. Karlsson, J.G. Quintiere, Enclosure Fire Dynamics, Boca Raton, USA, CRC Press, 1999.

[30] L.G. Bela, Instrument Engineers' Handbook: Process measurement and analysis, fourth ed., USA, CRC Press, 2003.

[31] Aaliant Div. of Venture Measurement, Mark V Target Strain Flowmeter Installation, Operation and Maintenance Manual M711, Revision B, 2001.

[32] L. Yi, Study on Smoke Movement and Management in Atrium Building, University of Science and Technology of China, Hefei, 2005. 
Table 1 Summary of tests

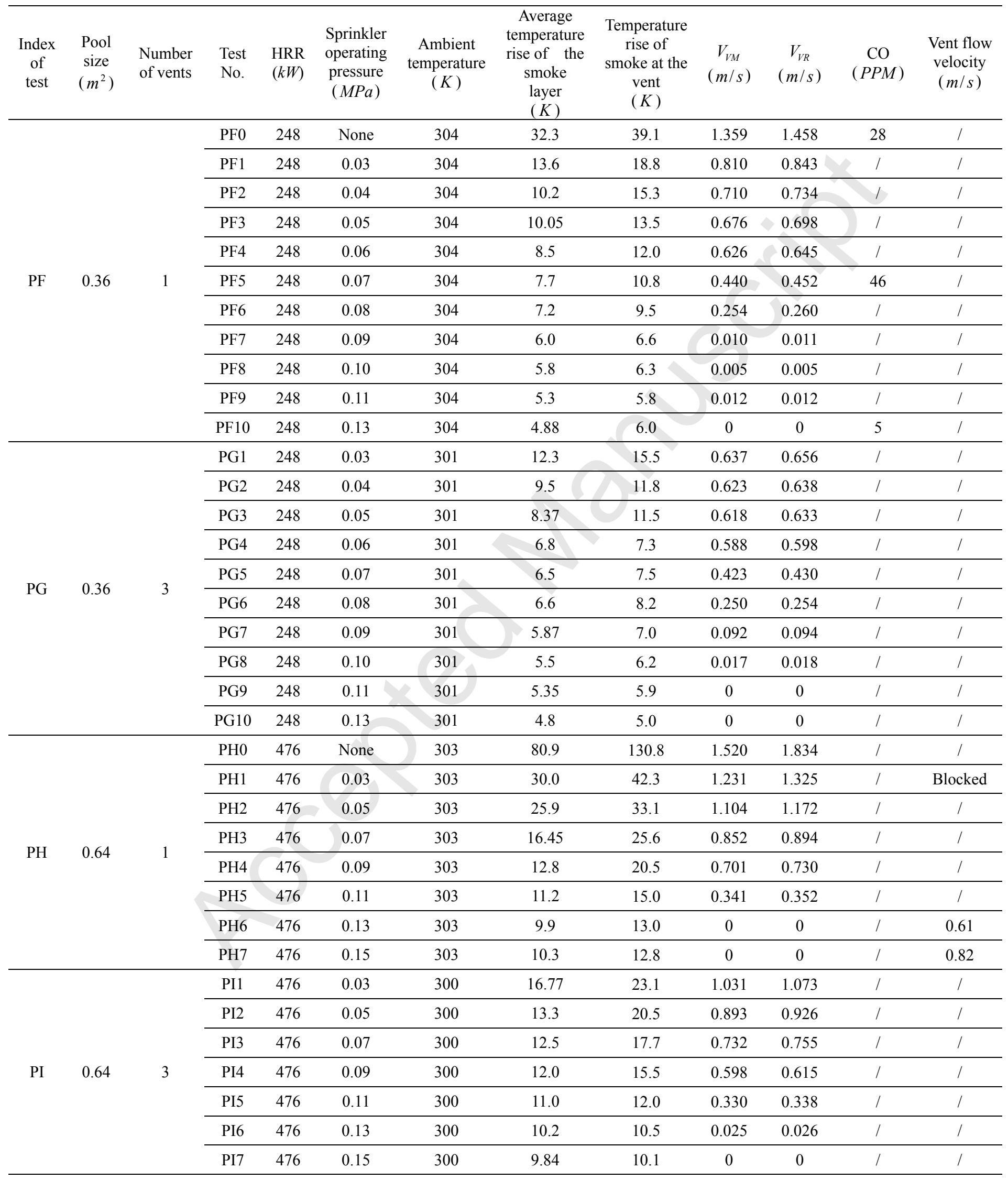




\section{$\underline{\text { Figure Captions }}$}

Figure 1 Schematic drawing of smoke venting without sprinkler spray

Figure 2 Target flowmeter

Figure 3 Experimental rig

Figure 4 Configuration of smoke vents

Figure 5 Smoke venting velocities measured in Tests PF and PH

Figure 6 Revised velocity of smoke venting with increase of operating pressure

Figure 7 Photograph of smoke venting state change under smoke venting failure (Test PF10)

Figure 8 CO concentration in Tests PF

Figure 9 Velocity of vent flow in Tests PH

Figure 10 Volumetric flow rate of smoke venting under different smoke venting conditions

Figure 11 Smoke temperature rise under different smoke venting conditions

Figure 12 Total volumetric flow rates under different smoke venting conditions

Figure 13 Smoke flow field under smoke venting logging 


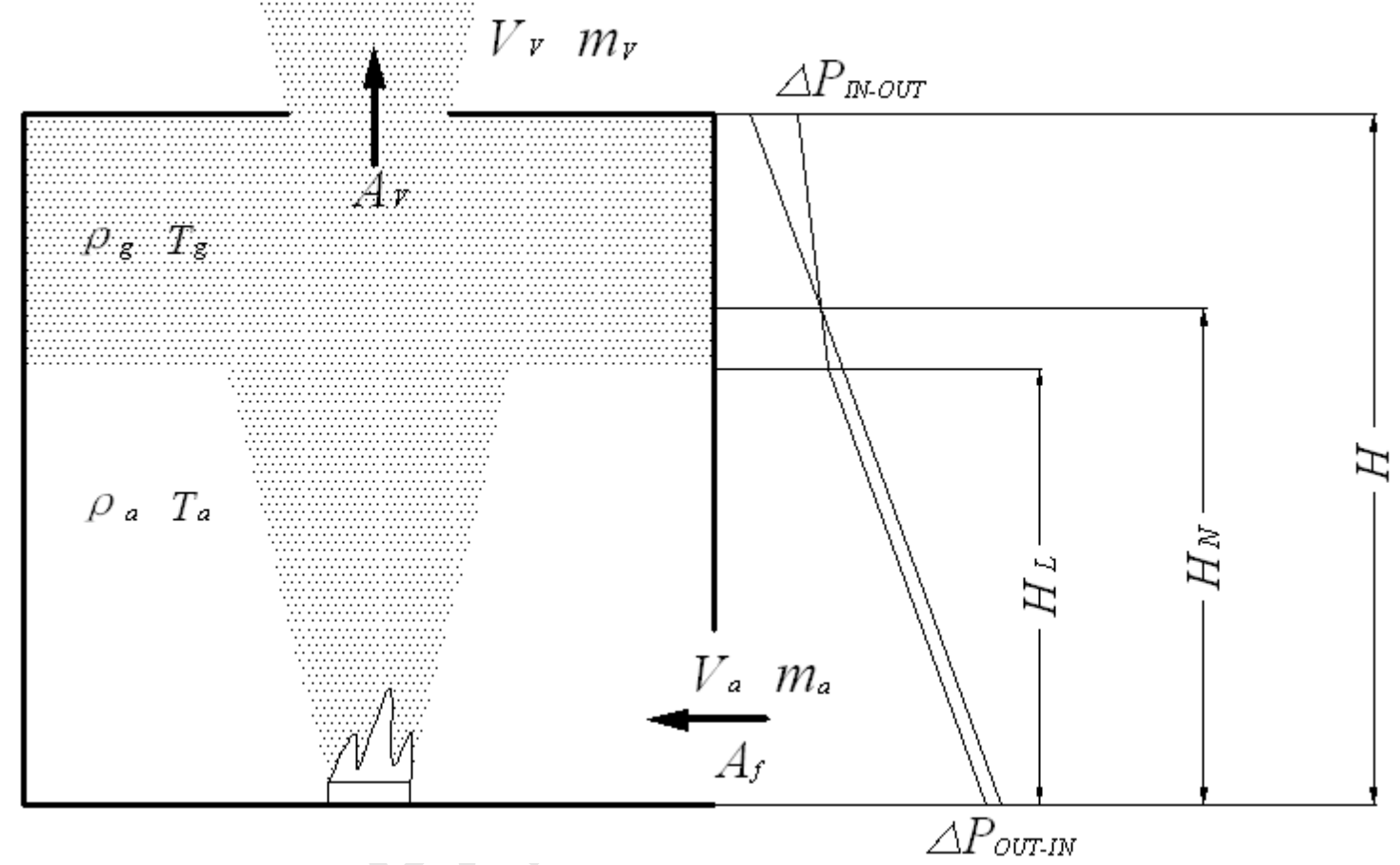

Figure 1 Schematic drawing of smoke venting without sprinkler spray 


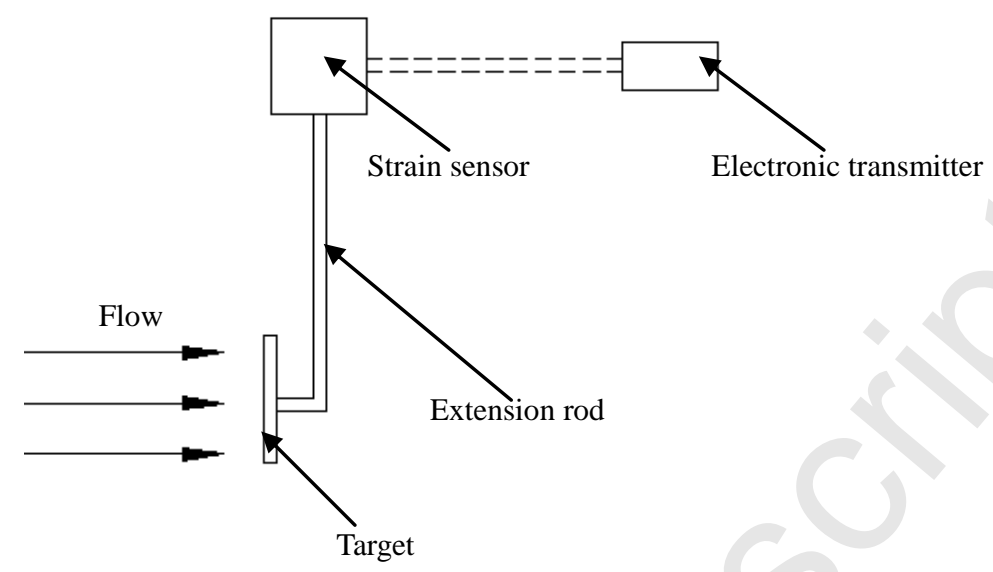

(a) Sketch drawing of structure of target flowmeter

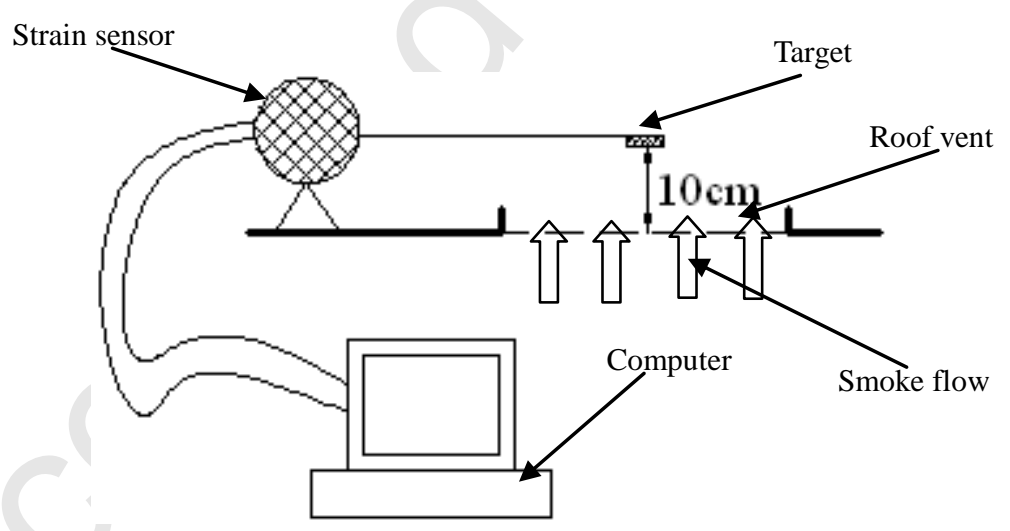

(b) Installation of target flowmeter

Figure 2 Target flowmeter 


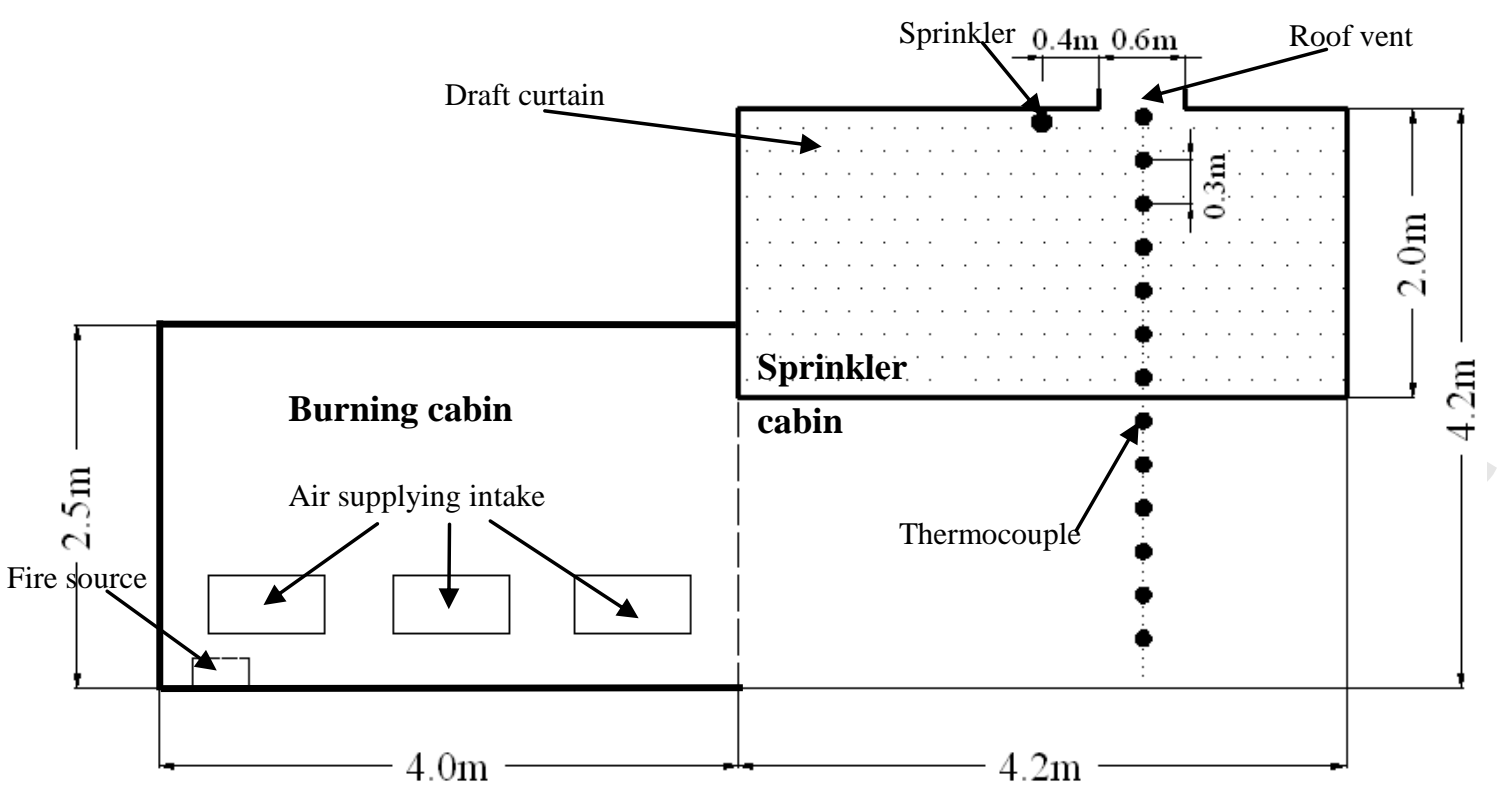

(a) Schematic view

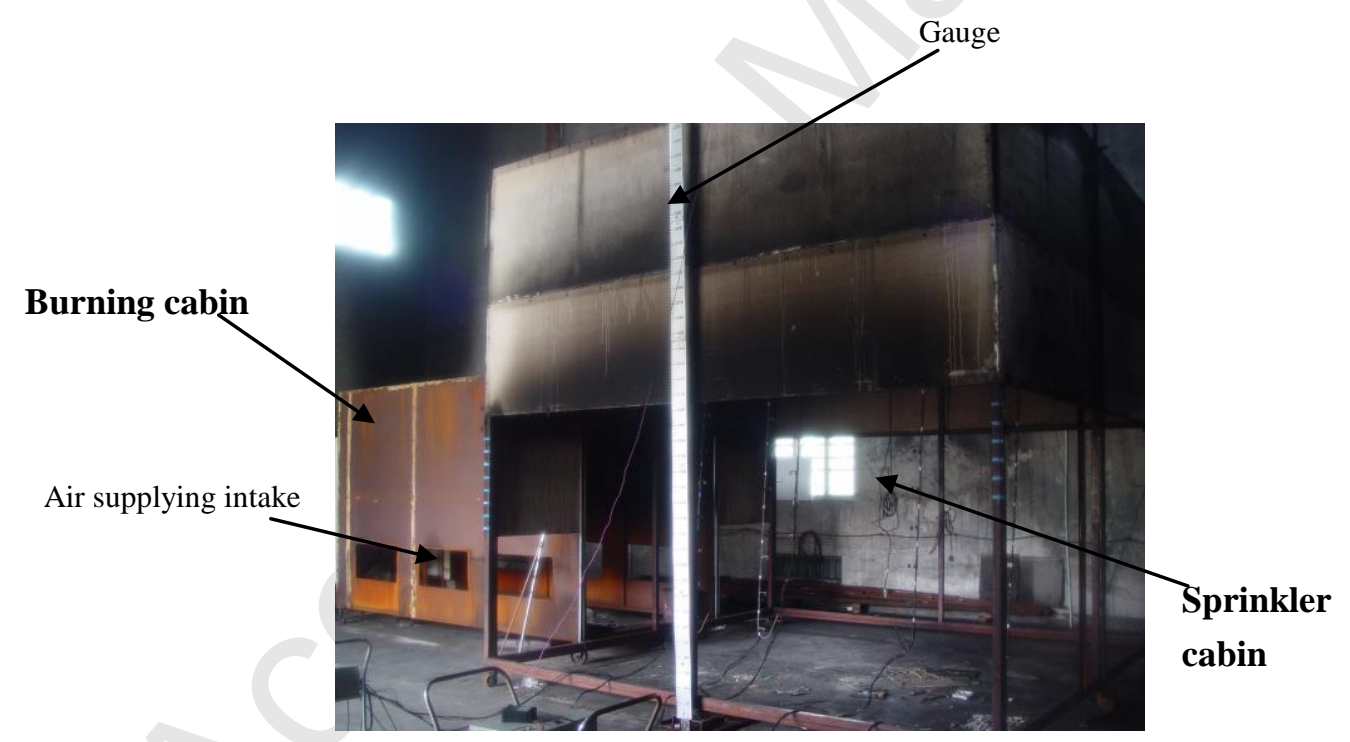

(b) Photo 


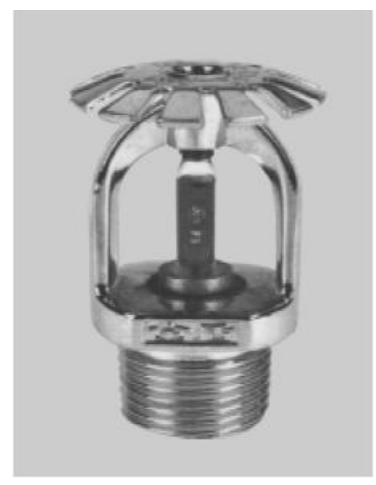

(c) Photo of the sprinkler

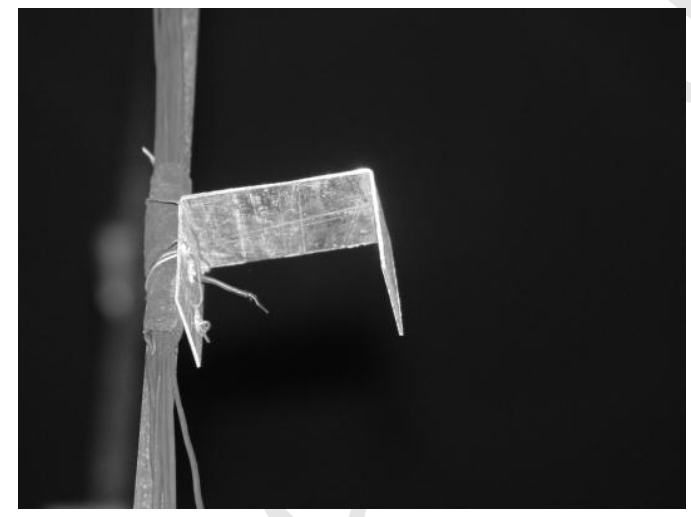

(d) Photo of thermocouple with the waterproofing cap

Figure 3 Experimental rig 


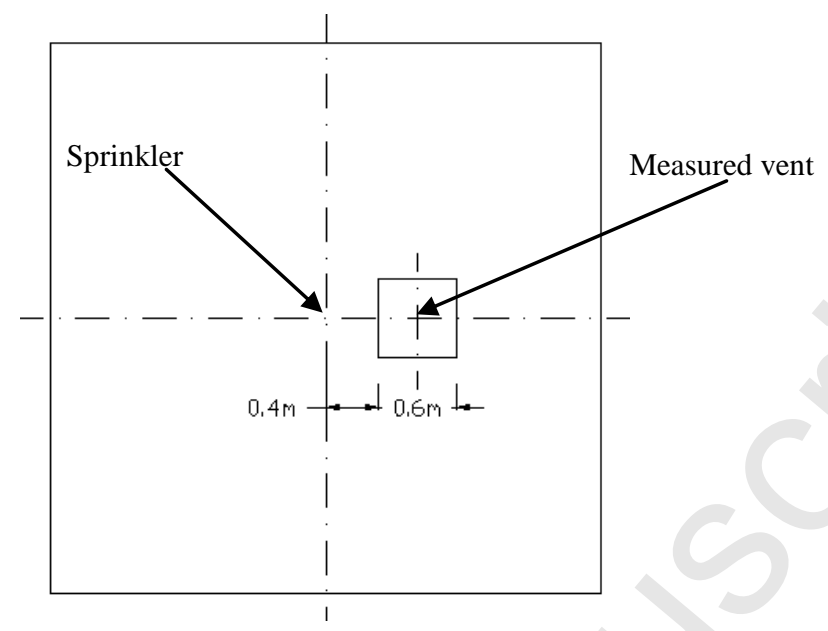

(a) Single roof vent

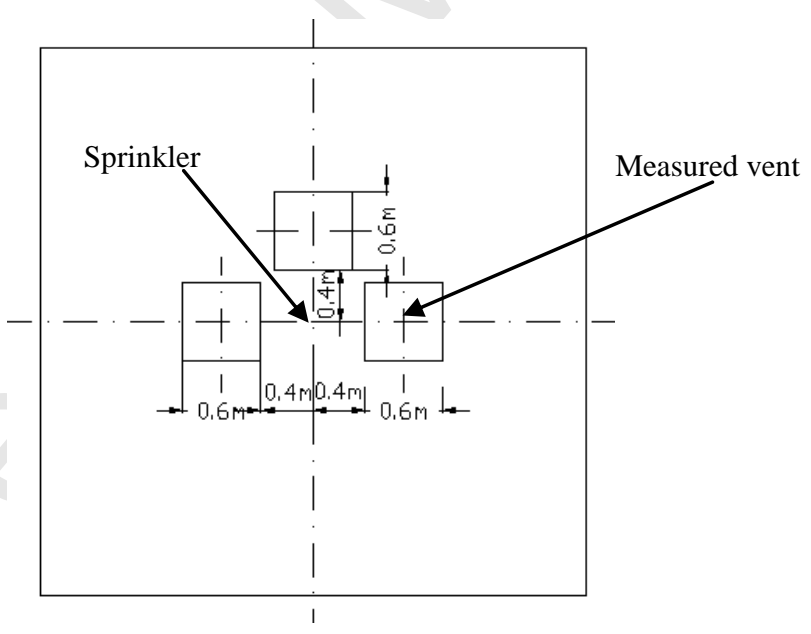

(b) Three roof vents

Figure 4 Configuration of smoke vents 


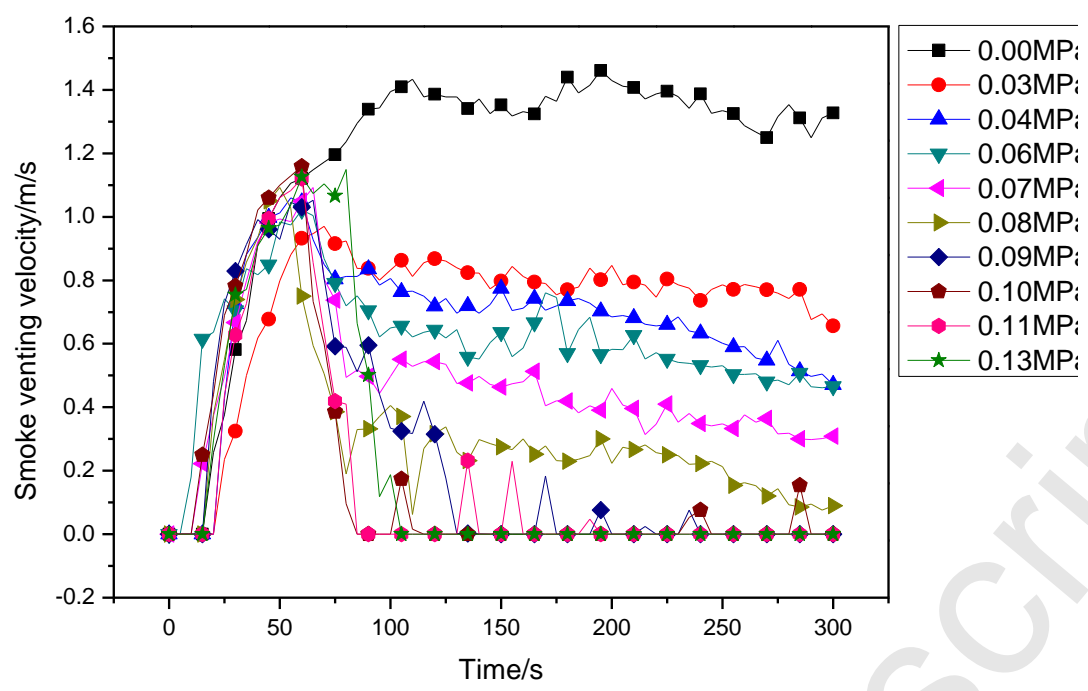

(a) Test PF (248 kW, square of $0.6 \mathrm{~m})$

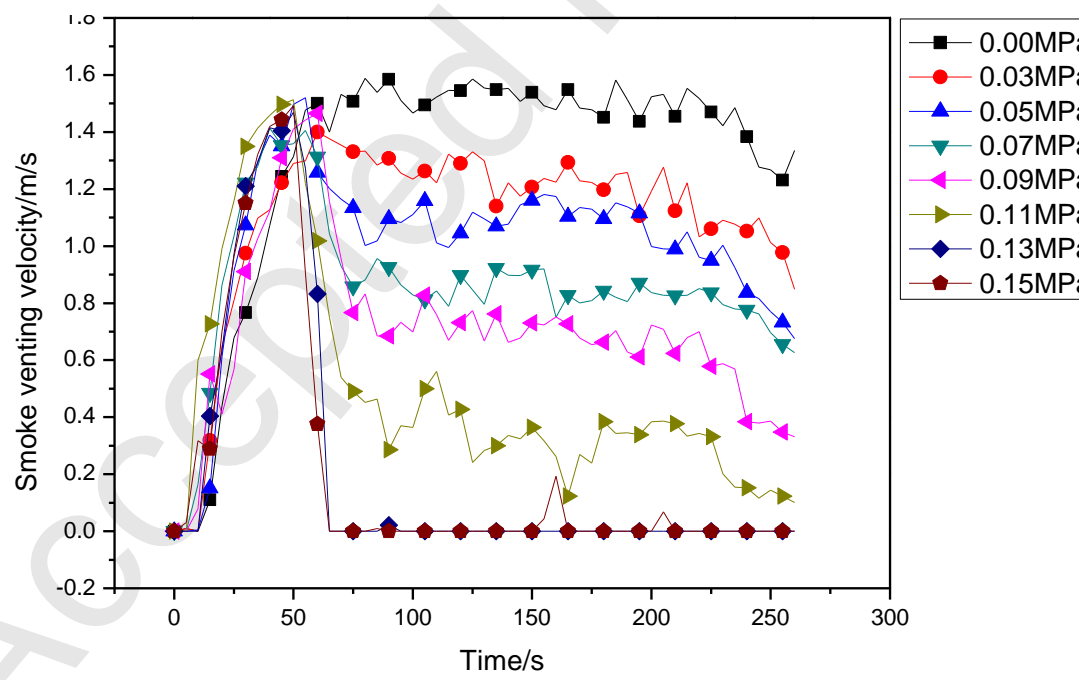

(b) Test PH (476 kW, square of $0.8 \mathrm{~m})$

Figure 5 Smoke venting velocities measured in Tests PF and PH 


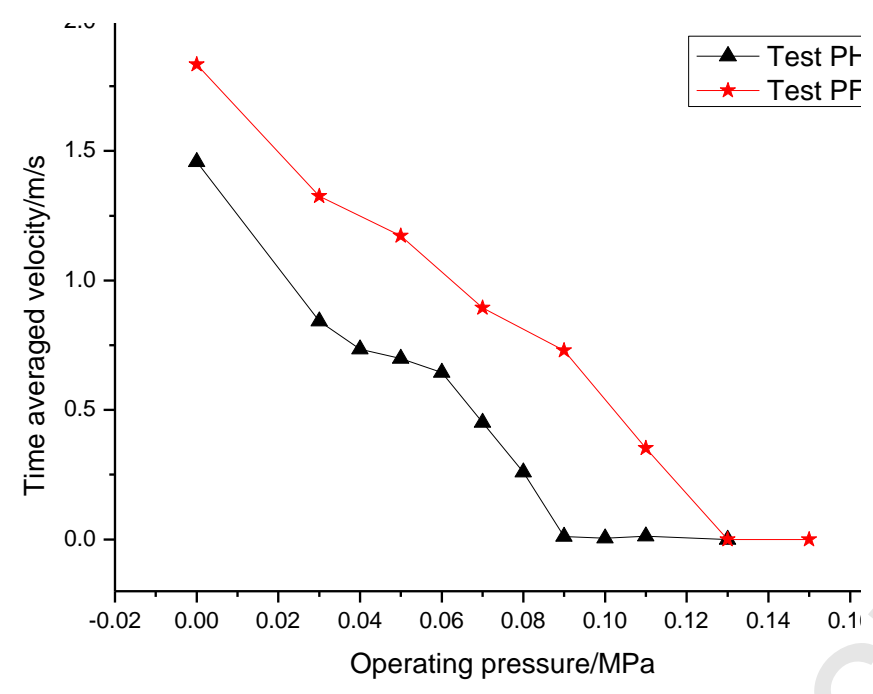

Figure 6 Revised velocity of smoke venting with increase of operating pressure 


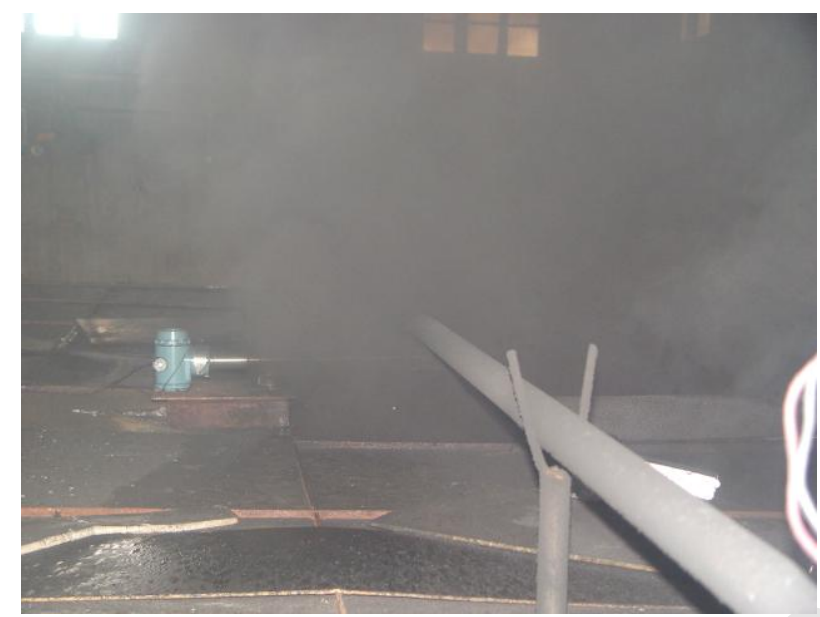

(a) Before sprinkler operating

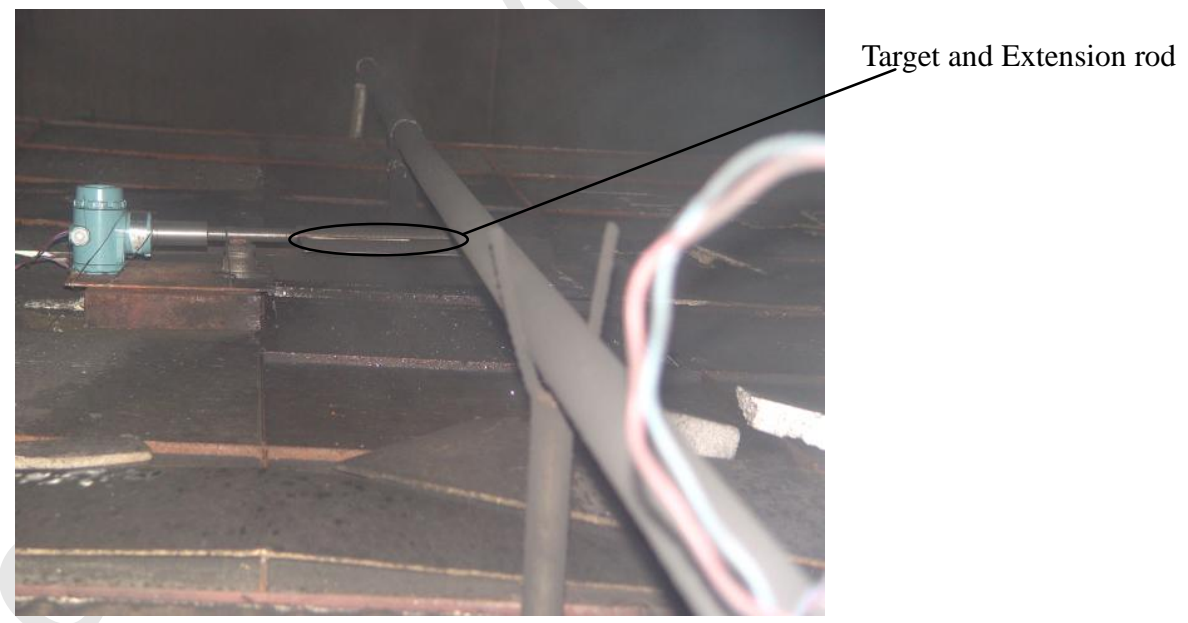

(b) After sprinkler operating (smoke venting logging)

Figure 7 Photograph of smoke venting state change under smoke venting failure (Test PF10, pictures are taken above the roof of sprinkler cabin) 


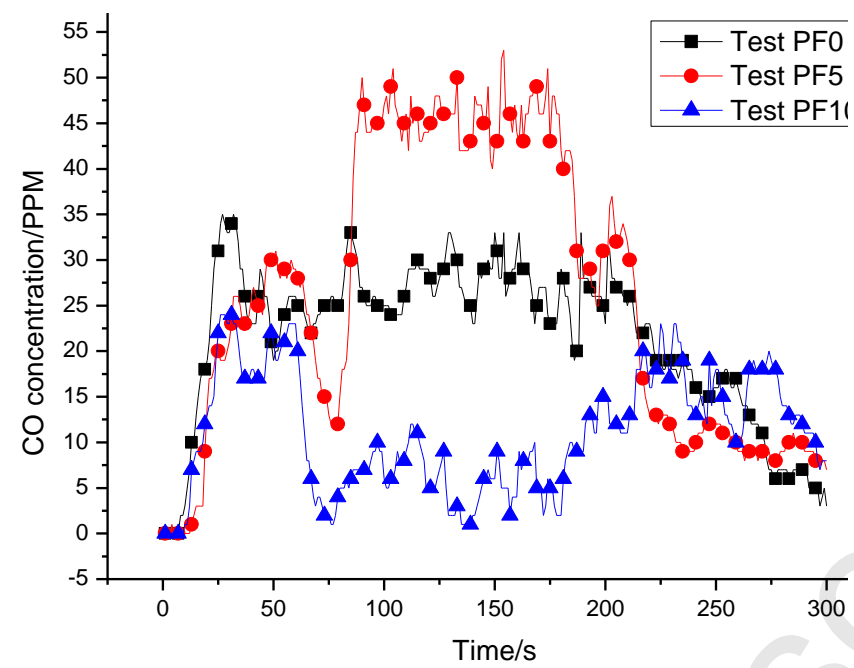

Figure 8 CO concentration in Tests PF

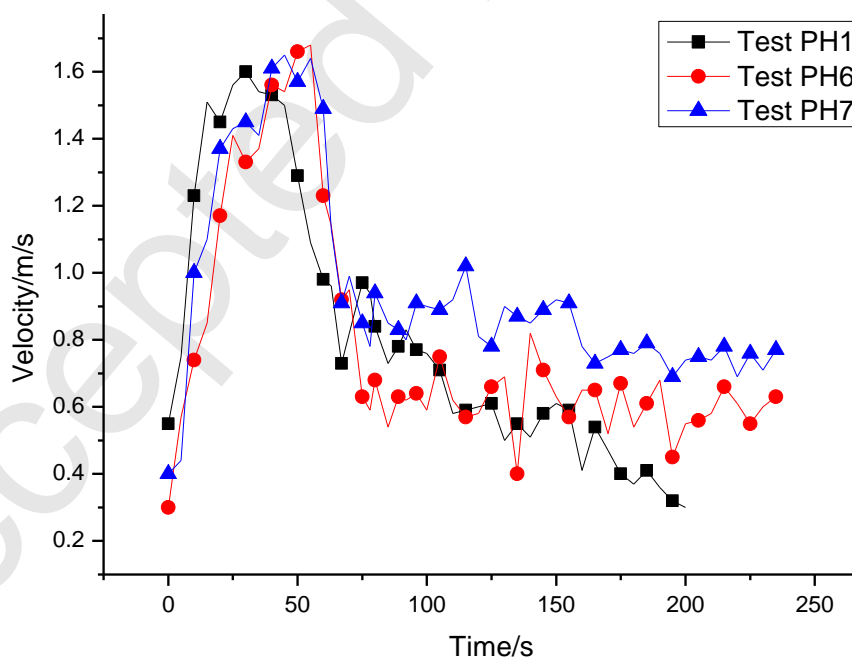

Figure 9 Velocity of vent flow in Tests PH (measured by the hot-wire anemometer) 


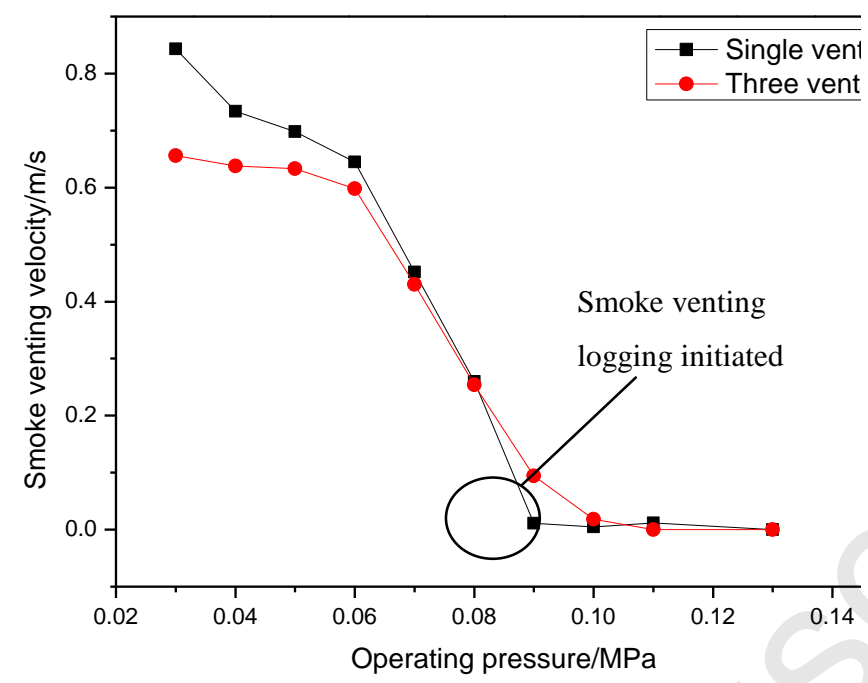

(a) Comparison of velocity in Tests PF and PG with low HRR

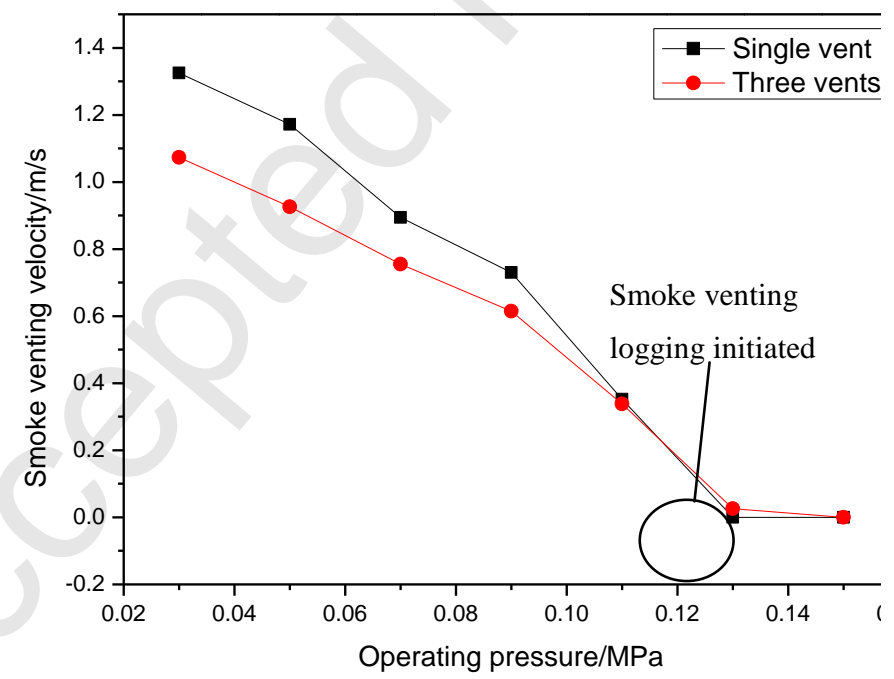

(b) Comparison of velocity in Tests PH and PI with high HRR

Figure 10 Velocities of smoke venting under different smoke venting conditions 


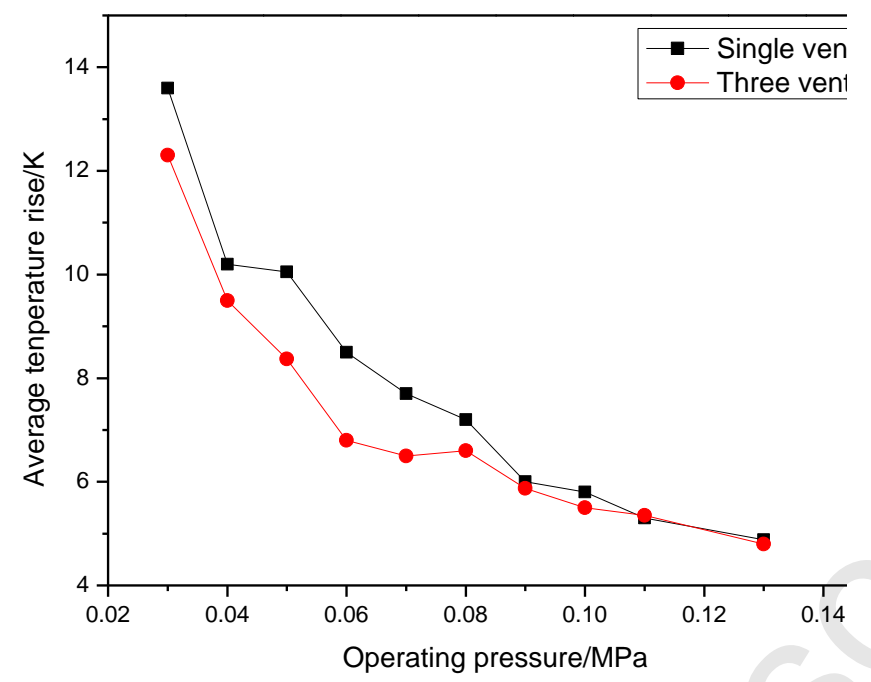

(a) Comparison of smoke layer temperature rise in Tests PF and PG with low HRR

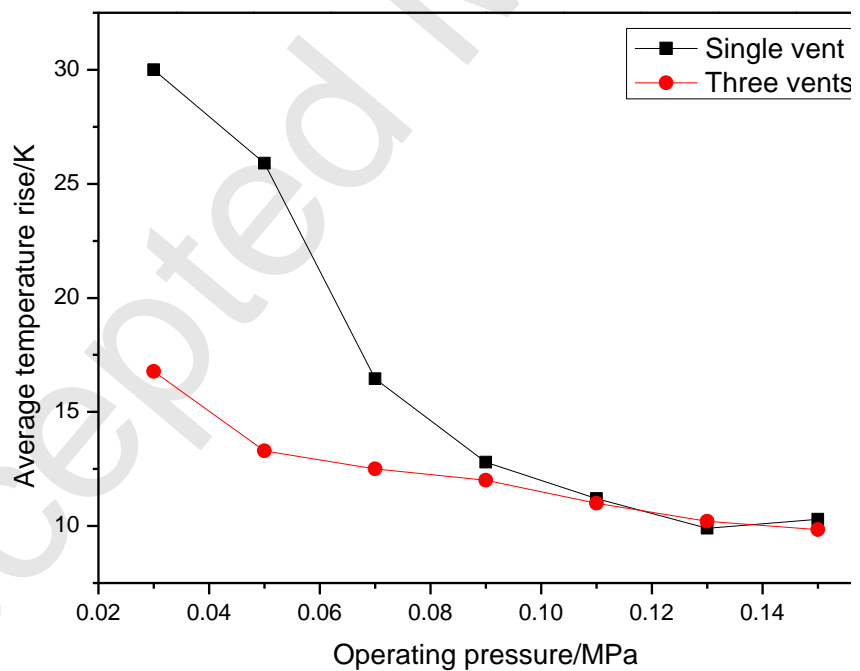

(b) Comparison of smoke layer temperature rise in Tests PH and PI with high HRR

Figure 11 Smoke temperature rise under different smoke venting conditions 


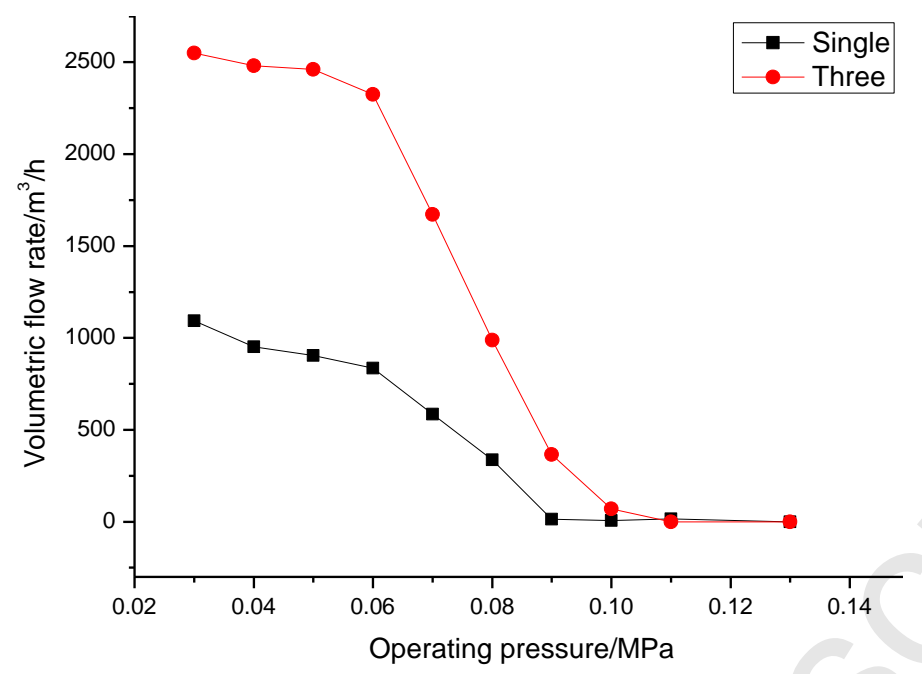

(a) Volumetric flow rates of smoke venting in Tests PF and PG with low HRR

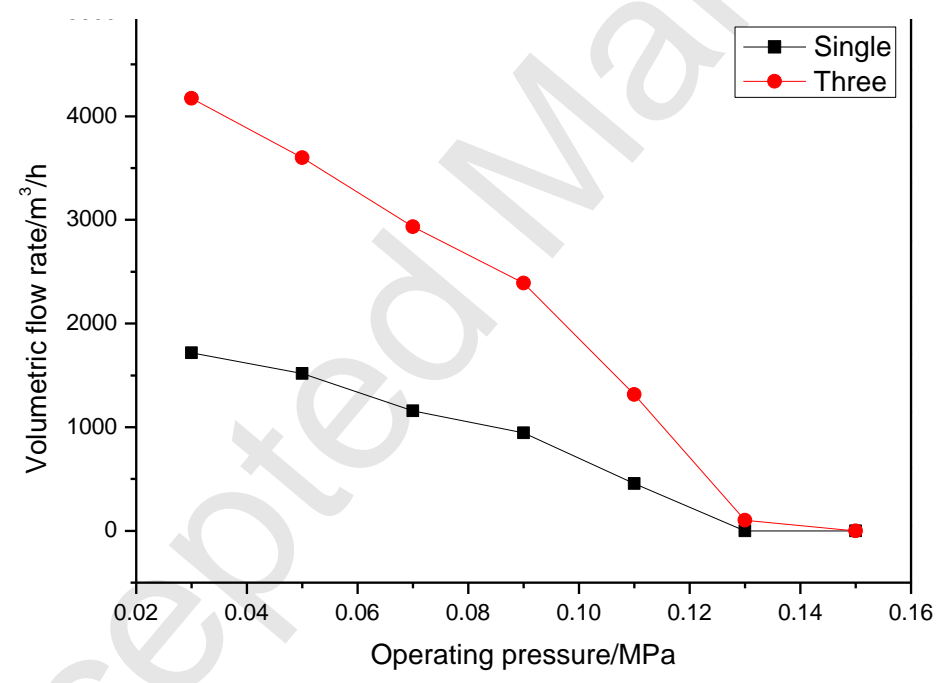

(b) Comparison of smoke layer temperature rise in Tests PH and PI with high HRR

Figure 12 Total volumetric flow rates under different smoke venting conditions 


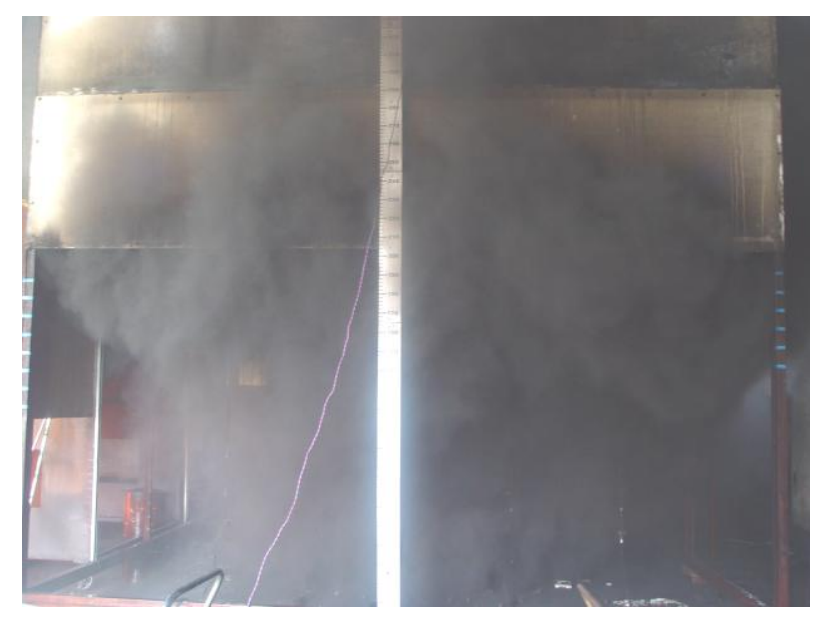

(a) Test PH7

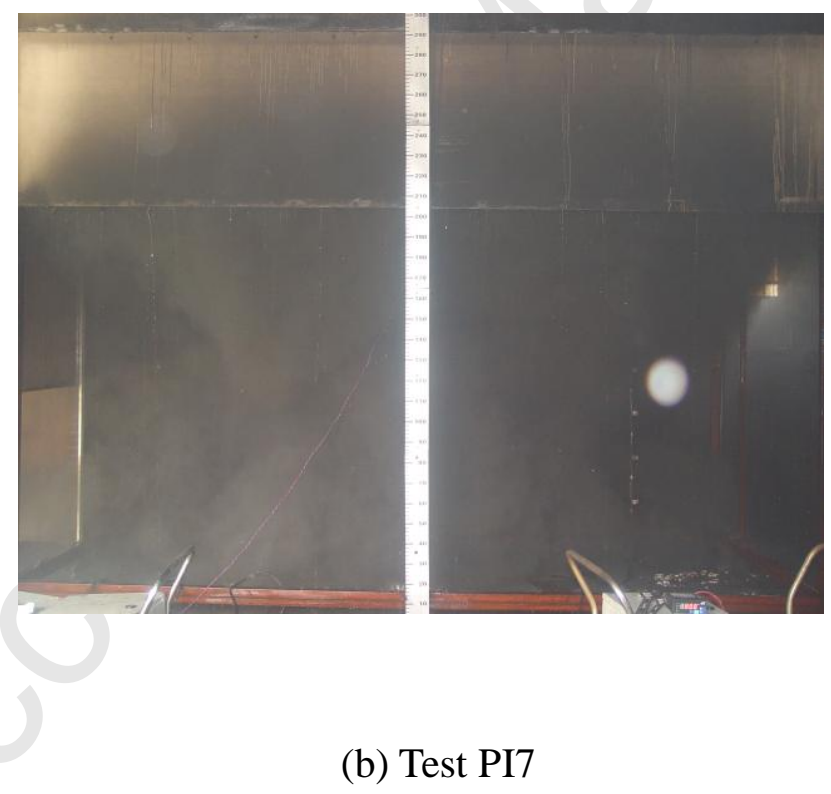

Figure 13 Smoke flow field under smoke venting logging 